\title{
Spreading of Innovative Technical Traits and Cumulative Technical Evolution: Continuity or Discontinuity?
}

\author{
Valentine Roux
}

Published online: 14 October 2012

(C) Springer Science+Business Media New York 2012

\begin{abstract}
This paper questions the spreading of techniques considered as advantageous when measured in terms of energetic efficiency. A present-day case study, in which techniques do not spread, is used to highlight a transmission model that can be used to understand the spread of technical systems in terms of demic or cultural processes. The model is then applied to the spread of the potter's wheel in the second and third millennium $\mathrm{BC}$ in the southern and northern Levant. Results show that both demic and cultural processes explain how the potter's wheel became prevalent in the Levant. The selective forces are discussed by comparing the ceramic production contexts. We conclude that technical evolution is regulated by social mutations, i.e., major discontinuities.
\end{abstract}

Keywords Diffusion · Technological system · Social learning · Potter's wheel $\cdot$ Levant $\cdot$ Bronze age

\section{Introduction}

This paper questions the spread of techniques considered as advantageous when measured in terms of energetic efficiency. These techniques, such as blade and wheel technology in the domain of lithics and ceramics respectively, have opened the path to new lineages of objects and can be considered as major milestones in the history of techniques (Simondon 1958). They have also modified the relationships of human groups with their environment, increasing (or diminishing) their capacities to endure (Creswell 1996). Their spread across the landscape is part of the process of technical knowledge accumulation and raises the question whether it reveals continuity versus

\section{Roux}

Maison René Ginouvès, 21 allée de l'université, 92023 Nanterre cedex, France

V. Roux $(\bowtie)$

CNRS, Université Paris Ouest Nanterre La Défense, Nanterre, France

e-mail: valentine.roux@mae.u-paris10.fr 
discontinuity in the history of ancient societies. Continuity refers here to gradual changes occurring in a circumstantial way on the middle or short term history, whereas discontinuity refers to anthropological changes, including social and/or population change, occurring on the long-term history as elaborated by Braudel (1958; see also Roux and Courty 2013). Previous technological studies have shown that major technical inventions seem to be determined by social mutations, indicating therefore discontinuities (e.g. Creswell 1994; Roux 2010). The question remains, however, how these inventions spread and whether their propagation is also determined by specific social conditions.

According to the Darwinian approach, the social mechanisms underlying the spreading of innovative traits are twofold: either these traits become prevalent through a process of "natural selection" (selective advantage to the group using these traits) or through a process of copy (because they are more effective in some way; for a simple taxonomy of social-learning strategies that involve copying, see O'Brien and Bentley 2011, p. 316; Shennan 2009). The former would reveal expansion of social groups, which is change in population or in social structures, and therefore discontinuities. The latter, being a process of endogenous or exogenous copy, would reveal contacts occurring in circumstantial situations, that is cultural changes, and therefore continuities.

In evolutionary archaeology, interpretations of the processes underlying spreading of traits call upon mathematical models linking demographic patterns (through distribution of ${ }^{14} \mathrm{C}$ dates, e.g. Collard et al. 2010) and/or patterns of cultural traits with demic or cultural change (e.g. Boyd and Richerson 1985; Shennan 2011). Copying strategies are mainly studied through diffusion curves (e.g. Kandler and Steele 2010; Henrich 2001). The relevance of the models lies in the hypothesis that contacts between people are necessary and sufficient for social learning to occur. However, numerous anthropological studies have shown that knowledge about a new behaviour is not a sufficient cause of its adoption (Schiffer 2008, 2011) and that the nature of the relationships in between interconnected social groups as well as the nature of the trait itself impinge directly on the diffusion of these traits (e.g. Gelbert 2003; Gosselain 2000, 2008; Lemonnier 1993).

At this stage of research, it seems important therefore to first assess social learning models against empirical data in order to strengthen our interpretation of archaeological data. In this perspective, and in order to highlight patterns significant for demic versus cultural process, I propose to examine the microevolutionary mechanisms of cultural evolution in a present-day situation (as proposed by researchers like Mesoudi 2007, 2008; Mesoudi and O'Brien 2009). The objective is to highlight "regularities". The term "regularity" has been coined by Gallay (1986). Regularities are the reference data, or else the models, used in the necessary analogical reasoning involved in the interpretative process. They are based on recurrent empirical observations and belong to the anthropological domain. They do not integrate the factor "time" as opposed to the historical scenarios that are descriptive and contingent (Gallay 2011). Regularities can take different forms, either mathematical or verbal. In the latter case, they can be expressed under the form "IF $\{P\}$, THEN $\{\mathrm{Q}\}$ " (Gardin 1980). Their foundation lies in their explanatory mechanisms whose study aims at pushing up the regularities to the rank of general laws. Within the framework of this study, the sought-after regularities relate to the conditions favourable to the spreading of 
technical traits and their explanatory mechanisms call upon social psychology. They will be applied to the archaeology of the second and third millennium $\mathrm{BC}$ of the southern and northern Levant in order to reconstruct the historical scenarios and highlight patterns of cultural macroevolution.

The focus will be on the wheel coiling technique. It represents a major advance in the history of ceramic techniques when considering its techno-economic performance (gain in manufacturing time and in regularity of the finished product). In the southern Levant, it was invented by the mid-fifth millennium $\mathrm{BC}$, but its wide adoption dates only to the beginning of the second millennium BC. In the northern Levant, it was in common use by the mid of the third millennium BC. The question is whether in each case the generalised adoption of the potter's wheel results from a process of "natural selection" or copy.

As we shall see, our results show that, depending on the regions, the diffusion of the wheel coiling technique occurred through either demic or cultural processes, indicating therefore either discontinuity or continuity. However, these different historical scenarios were actualised within comparable conditions of production. We conclude that the spreading of the potter's wheel was determined by the evolution of social structures and, by consequence, that cumulative technical evolution appears as regulated by major social changes, namely major discontinuities.

\section{Microevolutionary Mechanisms of Cultural Evolution: Indian Potters as a Case Study}

Anthropological studies in the domain of techniques have shown that technical traditions are very good markers of social boundaries in which there are nonborrowing phenomena in between these groups (e.g. Lemonnier 1993; Stark 1998; Stark et al. 2008). In the case of endogamous societies, these boundaries correspond to the perimeters of the learning networks (e.g. Gallay 2007). Nonborrowing between endogamous social groups can be explained by reference to cognitive and social learning theories according to which techniques are learned through both individual (constructing skills through experiments) and social learning (learning according to a model) (Reed and Bril 1996; Bril 2002). As a result, the process itself of apprenticeship of craft skills creates strong cognitive relationship between craft techniques and social identity (the model's one), favouring the confinement of these techniques to the perimeter of the social group within which the craft is learned and transmitted (e.g. Degoy 2008; Gosselain 2008; Ingold 2001; Knappett 2005).

However, there are situations where technical features disseminate across these social boundaries. Such dissemination raises the issue of the conditions for the spreading of innovative technical traits and the triggering of social learning.

In this section, I report on a present-day case study relating the non-borrowing of advantageous technical traits in between two groups of potters who have co-existed in the same region for more than 200 years. I first describe the potters and assess the generality of the situation by comparing it to cases taken on the longue durée and by calling upon socio-psychological explanations. I then discuss social learning in relationship with processes of diffusion. 
The case study takes place in North West India, in the Bulandshar district, Uttar Pradesh, $100 \mathrm{~km}$ east of Delhi. This area covers roughly $200 \mathrm{~km}^{2}$ and is inhabited by Hindus and Muslims. The Hindus are the most ancient population, while the Muslims came from the Indus valley through successive waves of migration between the fifteenth and the nineteenth centuries. Muslim potters, called "Multani Kumhar" (potters from Multan), came along these migrations (Saraswati and Behura 1964; Sodhi 2006) and are distributed among 50 villages. Number of potting families per village varies from 1 to 50 families.

The Hindu potters, also called "Prajapati", use the fly wheel, make a wide range of utilitarian non glazed pots and fire their vessels in open firings. The Multani potters use the foot wheel, make glazed and non-glazed utilitarian pots and use vertical updraft kilns (Fig. 1). When comparing the properties of the manufacturing techniques used by the Prajapati and the Multani potters, the latter can be considered as more advantageous than the former when measured in terms of human energy, quality of finished product and risks. The foot wheel enables the control of the speed all throughout the forming process. In contrast, the speed of the fly wheel cannot be controlled. It decreases progressively once launched. The glazing technique is mainly applied on cooking pots, which then present less permeability and better thermal properties than the unglazed ones. The kiln also creates advantages over the open firing since it enables better control over the rise in temperatures as well as less risk against wind or humid weather.

The Muslim and Hindu potters live side by side in the same villages. In most cases, they are in close contact, visiting each other often. The techniques used by the Muslims are therefore well known by the Hindus who are able to describe them very precisely.
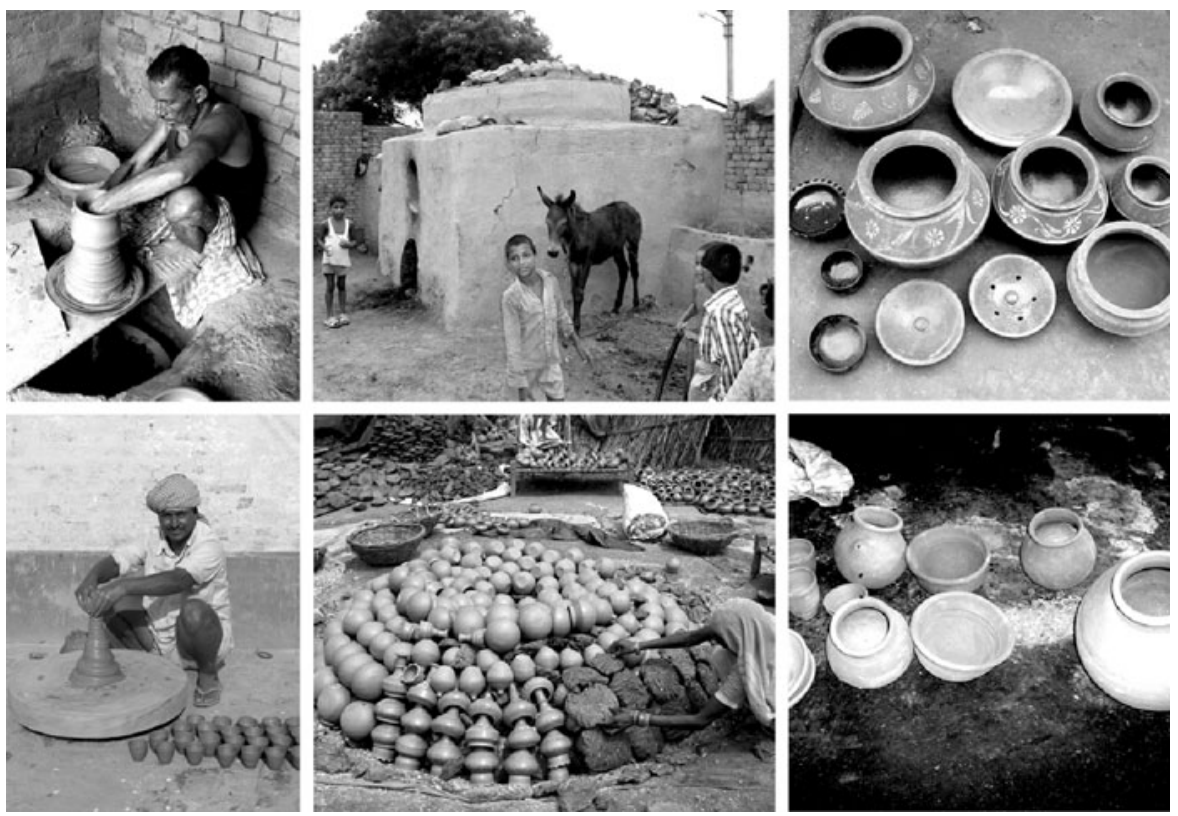

Fig. 1 Top Multani technical system. Bottom Prajapati technical system 
Up to 30 years ago, Muslims and Hindus had their own networks of clients. The Hindus used to be dependent specialists, providing Hindu families with pottery in exchange for cereals, mostly wheat. This barter system, known as the "jajmani" system, started to decline with the arrival of plastic and aluminium vessels. As a result, nowadays, most of the Hindu potters are turning to other jobs. The ones who keep up with pottery making live in towns and became specialists in the production of small vessels (like tea or milk cups). There are also a few examples of Hindu potters getting involved in the market economy and who sell a large range of vessels by direct sales or weekly fairs. As for the Multani potters, since their arrivals, they work independently distributing their pots mostly by direct sale in villages and in weekly fairs and also indirectly through middlemen. At one time, they were selling mainly to the Muslim population, but more recently, they are slowly taking up the market often left behind by the Hindu potters, thus selling indifferently to Muslim and Hindu clients.

In the last 200 years, the Hindus have never borrowed any of the technical instruments used by the Muslims except for one case discussed below. They can perceive the advantages of the Multani instruments, but are not interested in any borrowing. They have all sorts of different explanations (symbolic, technical, economic and functional) justifying the efficiency of their technical system and therefore the pointlessness of borrowing the Multani instruments. For example, they say that there are not interested in the kiln because they do not want to wait $5 \mathrm{~h}$ loading it with wood, they do not need to fire at a high temperature, it takes too much space, or because kilns are not well adapted for the firing of small vessels.

In summary, even in a strongly constrained economic situation (highly competitive market economy), the so-called advantageous technical tools are not necessarily adopted. This is observed in a context of production characterised by distinct endogamous social groups having each of them a proper technical system, that is to say a diversified socially and technologically context of production.

This situation of non-borrowing advantageous traits is not unique. On the contrary, there are numerous case studies where non-borrowing takes place such as the lack of diffusion of New Guinea bark capes (so useful when it rains) among interconnected groups (Lemonnier 1981). More striking is the observation of such a situation on the longue durée in the southern Levant. Here, between the fifth and the third millennium $\mathrm{BC}$, the potter's wheel was in the hands of a small group of specialised potters attached either to the politico-religious elite or to palaces, and this technology did not spread to potters of other social groups (Roux 2008). This situation prevailed for more than 2,000 years.

Such regularity in actualist and historical narratives can be explained by calling upon socio-psychological mechanisms. By reference to the Prajapati discourses and behaviours, it appears that both mental representations constructed in the course of learning and the mechanism of conformity prevent social groups from copying technical traits. Conformity has received considerable attention among social psychologists (e.g. Henrich and McElreath 2003; Moscovici 1984; Richerson and Boyd 2005). It is considered a type of frequency dependence, and it involves an exaggerated tendency to follow the majority. The overall effect is to homogenise behaviour within social groups while increasing variation in between groups (e.g. Efferson et al. 2008; Henrich and Boyd 1998). As a result of the conformity mechanism, in a 
diversified socially and technologically context, individuals do as their group and do not copy the other groups. This can occur even in the case of efficient technologies and a highly competitive environment. Let me specify here that the cognitive behaviours in question could be specific to techniques and their underlying learning process in the sense that, in our case study, they do not come into play for decorative or morphological features, which are the object of borrowings between both communities.

The generality of the mechanism explaining the non-borrowing of technical traits can be countered with the exception mentioned earlier that consists of one Hindu family who borrowed the Multani kiln 30 years ago. This Hindu family borrowed it because, in their words, the kiln was more efficient than the open firing and thus more economical, in the context of the market economy. This technical discourse contrasts with the discourses loaded with cultural representations produced by the rest of the potter's community. It expresses a cognitive functioning that has enabled the potter to transcend the local cultural representations as well as the rule of conformity, enabling the circulation of a technical trait between the two communities. Today, there are ten families using the updraft kiln. They correspond to the potter's eight sons and to two neighbours who borrowed it from them. The copying of the kiln between the Hindu potters underlines the importance of social status in the borrowing process, whereas the one borrowing of the kiln 30 years ago illustrates that, as for innovation, technical borrowing can depend on the cognitive expertise of a sole craftsman, corresponding in this regard to a random phenomenon (Roux 2010).

The architecture of the Prajapati kiln differs from the Multani one (Fig. 2). The latter presents a square foundation into which a circular updraft kiln is built. The Prajapati kiln is much simpler. It does not have any square foundation and is lower in height. The copying is thus not a perfect replica. The Prajapati potter who built it for the first time did it in fact without any help and went for a simple shape after some oral instructions. The specific architecture of the Prajapati kiln and its method of building support here the hypothesis that non-borrowing of the Multani kiln is not due to any learning or teaching costs, but to complex socio-psychological mechanisms.

Actualist and historical data thus reveal a recurrent social learning behaviour in diversified socially and technologically context of production that consists of the nonborrowing of advantageous technical traits given learning and conformity mechanisms that play on the perception of techniques and their properties. Given the generality of the mechanisms explaining the recurrent social behaviour, we propose to state the following regularity: in diversified socially and technologically context of

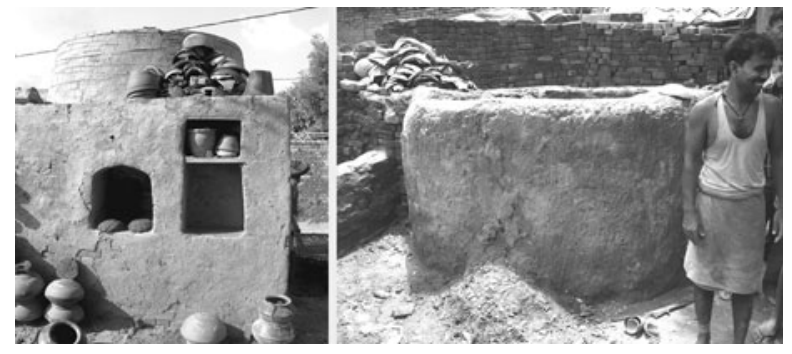

Fig. 2 Comparison between Multani (left) and Prajapati (right) kilns 
production, no borrowing of technological systems in between distinct social groups is expected; if expansion of one technological system to the detriment of another occurs, it will signal the expansion of one social group to the detriment of another and therefore demic diffusion. Thus, nowadays, the contemporary Multani technical system is expanding to the detriment of the Hindu technical system signalling the progressive abandonment of the job by the Hindu potters, and their replacement by the Multani potters. In other words, it signals in the region a major rupture with a change in the potter's population along with the end of the jajmani system and its replacement by the cash economy.

As discussed above, one technical trait belonging to a community can be copied by an individual from another community. This copying process, which consists in integrating a technical trait in a pre-existing technical system, signals circumstantial events as when one Hindu family borrowed the Multani kiln. Change in one technical trait only has to be clearly differentiated from change in technical systems understood here as an ensemble of techniques, instruments, skills, knowledge, and representations (Lemonnier 1993). The former indicates continuity, whereas the latter discontinuity.

\section{Cultural Macroevolution: Second Millennium BC Southern Levant}

In the southern Levant, the wheel coiling technique became prevalent by the beginning of the second millennium BC. In order to understand how this spread occurred, ceramic technical traditions have been examined at a macro-regional scale for the period preceding the diffusion of the potter's wheel, that is the Intermediate Bronze Age (also called Early Bronze Age IV, circa 2300-2000 BC) and the period witnessing the spread of the potter's wheel, that is the Middle Bronze Age (circa 2000-1500 BC).

The Intermediate Bronze Age period witnesses the disappearance of the fortified cities and towns that had characterised the first period of urbanisation of the southern Levant and which took place during the third millennium BC. The typical settlement became once again an open village. The populations were, depending on the regions, rural and semi-sedentary as suggested by the short-life span of the sites and the burial customs (Dever 1995; Gophna, 1992, 2009). Ceramic traditions have been examined on sites of different sizes and located in different ecological settings (Roux in press). They are all characterised by handmade forming techniques, regardless of vessel size, be it small open vessels or big closed vessels, or function (lamps, jars, jugs and cooking pots) (Fig. 3a). There is no evidence of a rotary device in production. The general lack of symmetry of numerous vessels suggests a low production. Variability of clay materials points to various places of production while the typological variation between the regional pottery groups expresses the diversity of the social groups occupying the southern Levant (e.g. Goren 1996; Maeir 2010). These different features suggest that pottery production was at the household level.

By the beginning of the second millennium BC, Palestine witnesses radical changes. Numerous Intermediate Bronze Age sites disappear, and new settlements ranging from hamlets to real cities appear. Along with the cities, huge earthen ramparts and monumental buildings are constructed. Middle Bronze Age sites often show a preponderance of either early (MBIIA) or later (MBIIB-C) ceramic material 


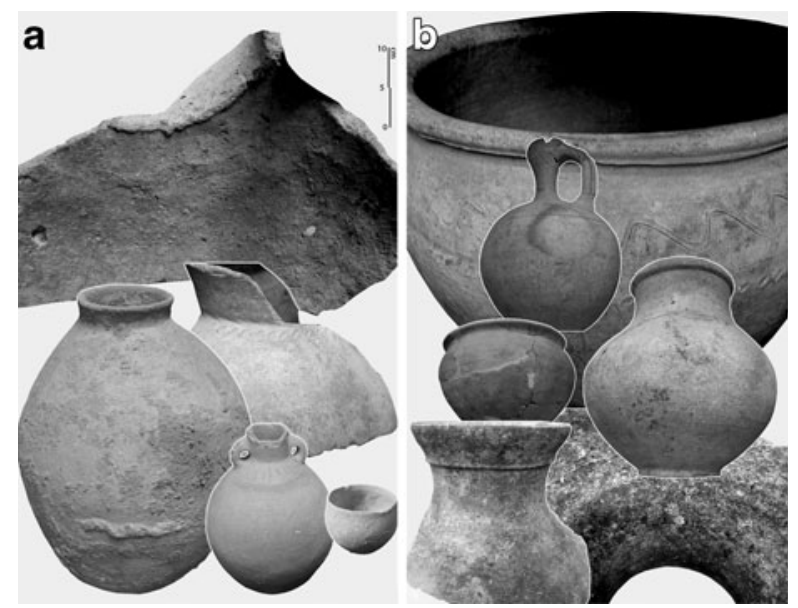

Fig. 3 Intermediate Bronze Age ceramics from southern Levant (a) and Middle Bronze Age ceramics from Tel Ifshar (b)

(Ilan and Marcus in press). The MBIIA is represented mainly on sites located on the coastal plain or in the inland valleys. The MBIIB saw a general trend of settlement expansion into new territory as in the Jordan valley (Maeir 2010).

The pottery of the Middle Bronze Age IIA shows a radical departure from the Intermediate Bronze Age as exemplified at sites like Tel Ifshar (Paley and Porath 1997; Marcus et al. 2008) or Aphek (Kochavi and Yadin 2002). These sites are among the most ancient Middle Bronze Age IIA sites found in Palestine. The ceramic assemblages are characterised by the combined arrival of new forms (northern style inspired) and the wheel coiling technique (e.g. Covello-Paran 2009; Ilan and Marcus in press). Indeed most of the vessels are wheel combed or wheel smoothed no matter the size of the vessels (Fig. 3b). It is therefore striking to see jugs and juglets finished the same way as big jars and kraters. The whole assemblage is henceforth made according to a new chaîne opératoire. As for the pottery of the Middle Bronze IIB, all the consumption and transfer vessels were wheel-made as exemplified at the site of Beth Shean (Roux 2009). Ceramic production was carried out in different specialised workshops as shown by petrographic and chemical analyses, which have revealed limited production centres (Maeir and Yellin 2007). No wheel has been found on Middle Bronze Age sites, but the type of tournette found in the later periods, the tenon tournette (Fig. 5c), originates in the north (Roobaert and Trokay 1990; Margueron 2004). It consists of three parts: a large clay upper wheel, the turntable, which rests on a basalt stone with a tenon fitting and pivoting inside a socket stone (Amiran and Shenhav 1984; Powell 1995). This tournette is radically different than the third millennium tournettes found in Palestine (Roux and Miroschedji 2009).

In summary, the Middle Bronze Age pottery technological system is characterised by the wheel coiling technique and the tenon tournette. It is found in combination with new pottery shapes. It was carried out in specialised workshops as shown by petrographic data on the site of Beth Shean and as suggested more generally by the skills involved in the use of the wheel coiling technique. This Middle Bronze Age technological and socio-economic system contrasts with the Intermediate Bronze Age one. Not only were the Intermediate Bronze Age ceramics handmade and their 
morphological and stylistic features different than those made in the Middle Bronze Age but also their context of production was different, most probably conducted at the domestic scale. In this regard, the Intermediate Bronze Age and the Middle Bronze Age socio-economic and technological ceramic systems appear to be radically different from each other. As for the rate of adoption of the Middle Bronze Age wheel system (wheel coiling technique and tournette), there is no progressive adoption from Intermediate Bronze Age to Middle Bronze Age. It appears in the first phases of the new established Middle Bronze Age IIA sites and is so widely disseminated that it seems to be adopted more or less instantly. If the curve of this adoption was quantified, the result would probably be what is called an $r$ curve, which is said to characterize "response to a major event, such that the population gets the information universally and more or less instantly rather than through social exchanges" (O'Brien and Bentley 2011). In the case of the southern Levant, such a diffusion curve can be interpreted in terms of replacement of population by reference to the sociological regularity highlighted above and according to which there is never borrowing of a whole technical system (fashioning technique, instrument and container shapes) between distinct social groups.

Concerning the origin of these Middle Bronze Age social groups, let us recall that the forms of vessels are new and are northern Levant style inspired ceramics (Beck 1985; Kempinski 1992, pp. 165-166). The tenon tournette is also northern origin. This suggests that the Middle Bronze Age ceramic tradition can be considered as a northern tradition brought into southern Levant with the arrival of northern groups. This hypothesis is in line with previous hypotheses formulated by Kempinski (1992) and Ilan (1995), according to which the Middle Bronze Age II wheel-made ceramics reflect the influence of migrant groups who penetrated the southern Levant along the Lebanese coast and later through the Orontes valley of Syria.

The rapid spreading of the wheel coiling technique in the southern Levant signals thus a major discontinuity in the history of the southern Levant. Once the new groups settled, the whole ceramic production was from this time forth achieved by specialised artisans organised in workshops. It is in this social context of production that in the southern Levant the potter's wheel was definitely implemented.

\section{Cultural Macroevolution: Third Millennium BC Northern Levant}

As shown previously, spreading of the wheel coiling technique can signal demic diffusion and therefore major discontinuous changes. However, this does not mean that the adoption of the wheel coiling technique signals per se population change, or else that the adoption of the wheel is never adopted through copying process, signalling "circumstantial" changes occurring on the moyenne durée. The case study is from the northern Levant, in Lebanon, at the site of Tell Arqa located north of Tripoli. It presents a continuous sequence of occupation from 2800 to $1800 \mathrm{BC}$ organised into five phases (from T to N, Thalmann 2006).

From a technological point of view, the ceramic assemblages from phase $\mathrm{T}$ to $\mathrm{N}$ show a very strong continuity in the ways of "doing". The continuity is indicated by the recurrence in clay preparation, manufacturing techniques, methods, and gestures whatever the category of container (cooking, storage, transfer or consumption 
vessels). The main fashioning chaîne opératoire found throughout the phases is illustrated in Fig. 4. It consists of fashioning the vessels on basalt fly stones. The base is first formed with a coil arranged in a spiral. It is thinned with the help of concentric discontinuous pressures followed by smoothing with continuous pressure. A peripheral coil is then placed on the base for the starting of the wall, and a second one is added at the inner junction base/walls to increase strength. Walls and necks are formed next by successively adding small coils joined together by pinching. The inner and outer faces are then respectively smoothed and combed. Once completed, vessels are left to dry upside down, with the neck against the ground. Depending on category of vessel, the junction between base and lower body, base and/or lower body are scraped or turned when leather hard.

The long-term preservation of this fashioning sequence testifies to the intergenerational transmission of a singular way of doing, a same "grammar" over more than one millennium. Such a transmission suggests, in return, a homogeneous social structure.

However, there are changes within this continuity. Technical changes consist mainly in the progressive use of rotary kinetic energy (RKE). The progression is visible in the types of vessels made with RKE. In phase T, RKE is used for preforming small goblets; in phase $\mathrm{S}$, small lamps and cups; in phase R, bigger vessels like pitchers; while in phase P (2400-2000 BC), all the vessels are preformed with RKE. The use of RKE during the first phases can be considered as a local invention limited in its application by the instrument, which was a simple one-sided convex circular stone (Fig. 5a). Its wider development in phase P corresponds to the replacement of these fly stones by the Palestinian basaltic tournette made of two wheels, the lower wheel with a biconical perforation and the upper wheel with a socket (Fig. 5b). This type of tournette, found at Arqa (Thalmann 2006), is well represented on Palestinian sites dated from the third millennium $\mathrm{BC}$ and is very efficient means for wheel shaping vessels of all shapes and sizes (Roux and Miroschedji 2009). Its adoption by the potters of Arqa seems to have been motivated by its performance properties (capacity for producing enough RKE for wheel shaping vessels of all shapes and sizes), which mark an improvement over the fly stones. Later, probably by the end of the third millennium $\mathrm{BC}$, it was replaced by the tenon tournette (Fig. 5c), the northern type described above and which is even more efficient than the Palestinian one.

Parallel to this technological evolution, the ceramic assemblage shows a progressive diversity in shapes and styles. Here, the morphological and stylistic features testify to the evolution of the social demand within a context of economic expansion (Thalmann 2006). This diversification can be analysed as emerging from interactions between multiple components. As mentioned above, the strong technical homogeneity of the assemblage over one millennium suggests that ceramic production was in the hands of a homogeneous social group. This is supported by the fact that while ceramic production got diversified and settlements were expanding in the surrounding plain, ceramic assemblages within this plain kept displaying highly similar technical and stylistic features during the different phases (Thalmann 2006).

In summary, at Arqa, the social context of ceramic production was socially homogeneous, and the adoption of the tournette fits well into a process of tool substitution that led the potters to use the RKE for shaping all the vessels. Had we 

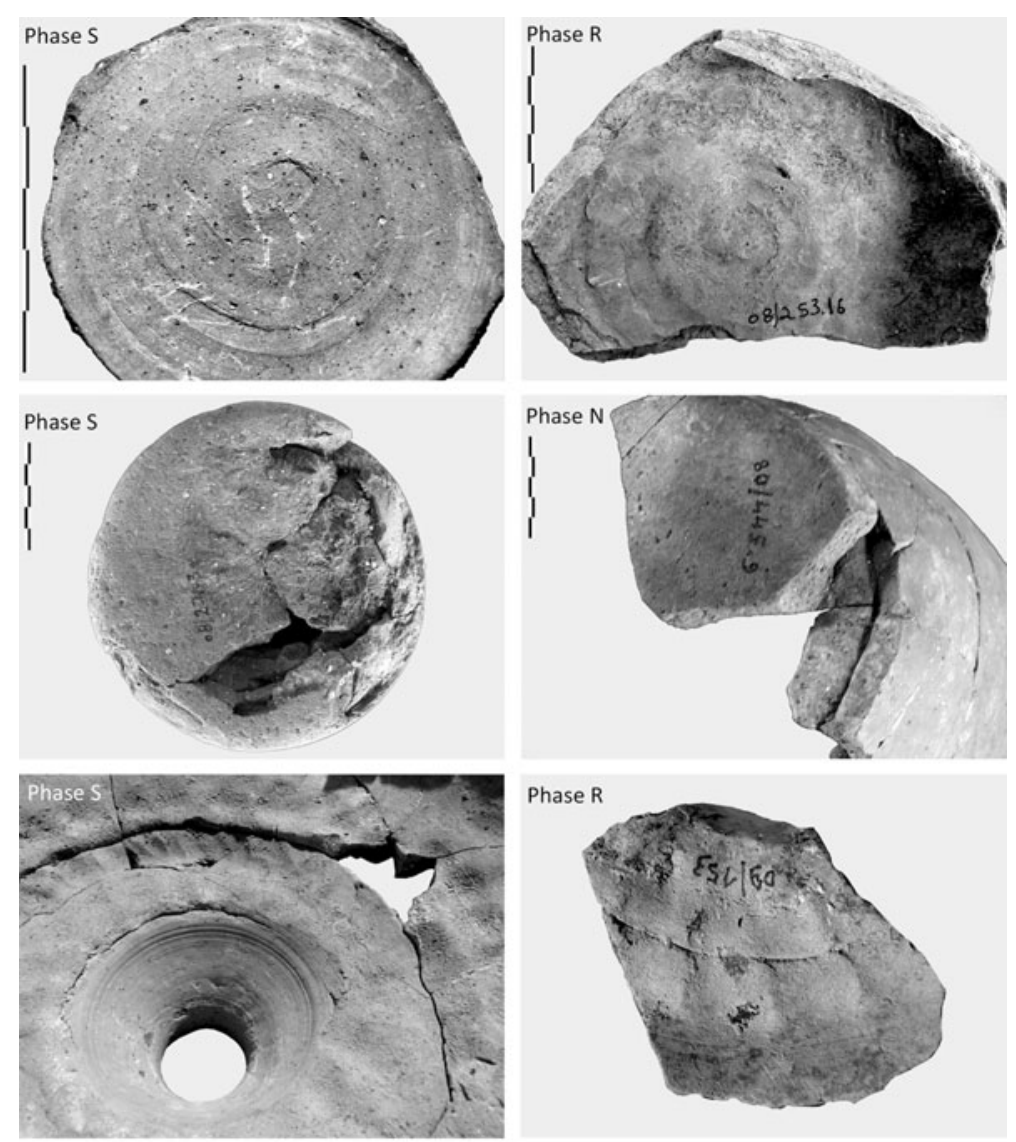

Phase R
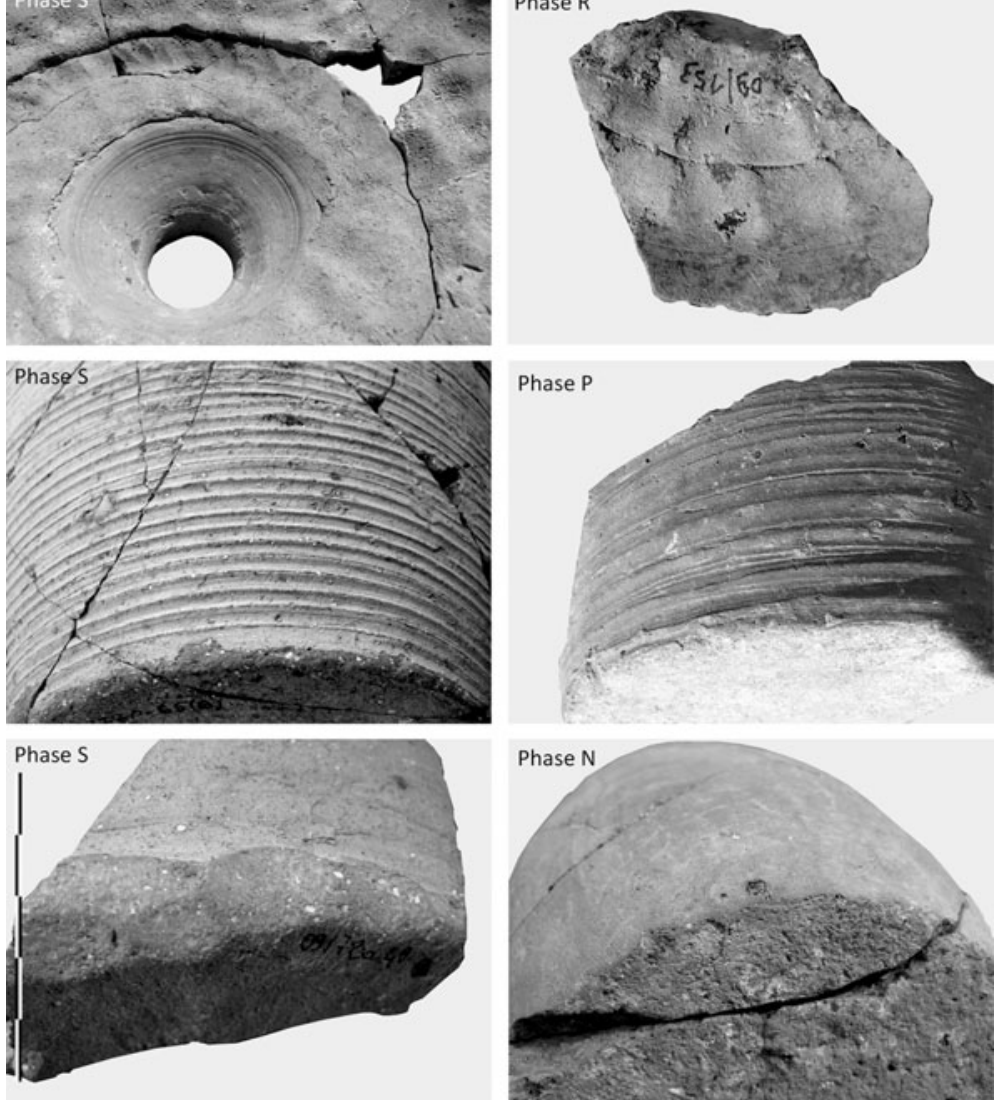

Fig. 4 The chaine opératoire at Tell Arqa from phase T to phase N. The different manufacturing stages are comparable in between the different phases 
a

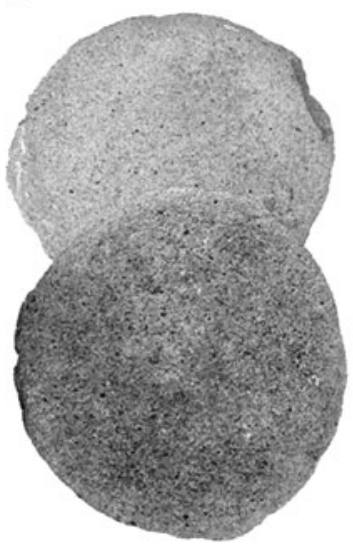

b

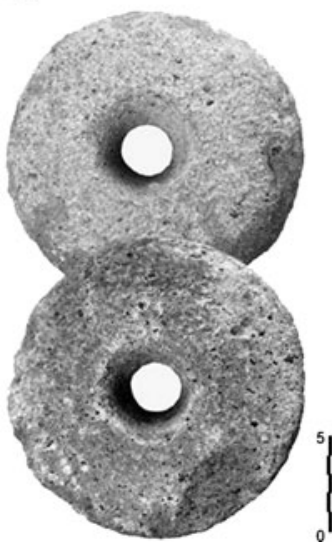

C

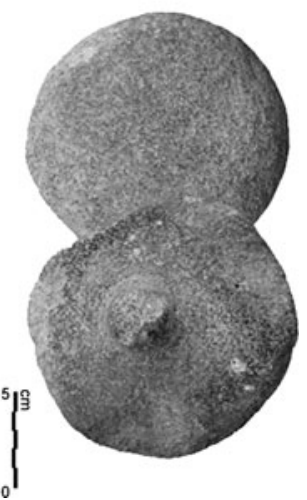

Fig. 5 The three types of rotary instruments found at Tell Arqa: a the fly stone, $\mathbf{b}$ the Palestinian. tournette and $\mathbf{c}$ the tenon tounette originating from Mesopotamia

quantified the curve of the adoption of the wheel coiling technique at Tell Arqa, we would have probably got an S-shaped diffusion curve, which plots "the cumulative frequency of adopters of a particular trait over some set period of time" (O'Brien and Bentley 2011, p. 319). The tail of the curve would have encompassed phases T, S and R. The sudden take off would have taken place at phase P. Such a diffusion curve is considered the result of social learning or else diffusion through cultural process. This is the case at Tell Arqa with, however, some nuances in the narrative. The growing number of wheel-made vessels does not correspond to a growing number of adopters, but to a technical change in the rotary instrument, which has been instantly adopted by the whole community of potters given its social homogeneity. In other words, local artisans have had contacts with foreign artisans in the course of which borrowing of efficient rotary instruments occurred. By reference to the sociological regularity highlighted above, the rapid change in phase $\mathrm{P}$ can be explained by a socially homogeneous context that favoured copying by all individuals of the group of a tool that was at first borrowed probably by only one individual. It follows that spreading of the wheel relates here to the middle term history in the same capacity as the morphological and stylistic features. In other words, it relates to the local historical dynamics and not to any major historical and/or social change.

In terms of the socio-economic context, from phase $\mathrm{P}$ onwards, the widespread use of the wheel suggests that the Arqa potters were specialised (Roux and Corbetta 1989). Now, the inter-generational transmission of ceramic ways of doing all throughout the third millennium suggests that ceramic production was in the hand of a socially homogeneous group. Therefore, craftsmen might have been specialised since phase T.

\section{Discussion}

In order to interpret spreading of technological systems in terms of continuity or discontinuity, a sociological regularity has been first highlighted based on actualist 
data collected in India. A different tack has been taken that contrasts with the evolutionary or behavioural approaches (Schiffer and Skibo 1997; Skibo and Schiffer 2001). Indeed, as compared to the transmission models proposed by evolutionary archaeology, there has been a strong emphasis on the nature of the social context in which transmission occurs. As we saw, this social context impinges directly on social learning. As compared to the behavioural model, the social context is not considered as one among the other parameters intervening in technological change. It represents the conditions for the actualisation of technological change as elaborated in the dynamic approach (Roux 2003).

The sociological transmission model proposed here states that depending on the context of craft production-socially diversified or homogeneous-spreading of a complex technological system occurs either through demic or copying process. The foundation of the model lies in its explanatory mechanisms. These mechanisms call upon socio-psychological behaviours, which could be universal as it is argued in cross-cultural psychology (Berry et al. 2002). Studies in evolutionary psychology also address the question of cultural evolution (e.g. Baum et al. 2004; Mesoudi 2010). However, it should be clear that socio-psychological mechanisms are here mobilised to explain sociological regularities only, but in no way historical narratives (Gallay 2011). Historical narratives are by nature contingent and specific. They are the particular expression of the law-like behaviours explained by the psycho-social mechanisms. In other words, small-scale micro-evolutionary mechanisms of cultural evolution cannot be linked directly to specific pattern of cultural macro-evolution, but indirectly through the law-like "regularities". Figure 6 illustrates the relationships between these different components of our scientific procedure.

In the framework of this study, the proposed transmission model applies to technological traits only. Indeed, it relies upon learning mechanisms while these

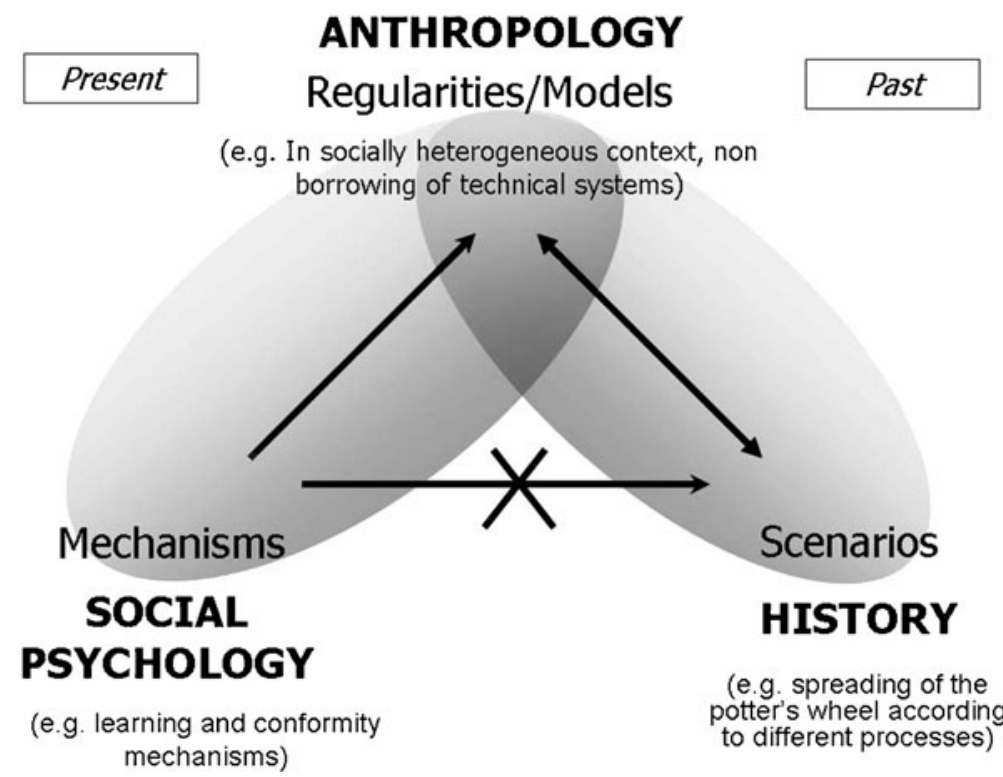

Fig. 6 A schematisation of our interpretative procedure (after Gallay 2011) 
mechanisms vary depending on the trait to be learned: Thus, the learning of a new shape does not imply the same mechanisms than the learning of a new technique.

This transmission model has enabled us to interpret archaeological patterns and highlight that the sole spreading of the wheel coiling technique does not signal per se continuous versus discontinuous change. In the southern Levant, the spreading of the wheel coiling technique to the detriment of the hand forming technique reflects demic diffusion. In the northern Levant, the spreading of the wheel coiling technique reflects cultural diffusion or else copying between craft specialists. In other words, both demic and cultural processes explain how the potter's wheel became prevalent in the Levant. They are the expressions of the different historical scenarios that recount for the adoption of the wheel in the Levant.

To take this one step further and better understand cumulative technical evolution, I propose now to compare the ceramic production context of southern and northern Levant, that is, the context into which both demic and cultural processes were actualised. The hypothesis is that it is at this level of analysis that evolutionary laws can be highlighted (Roux 2003). In both cases, the potter's wheel spread in a context where the whole ceramic production was in the hands of specialised artisans, unlike earlier times when the wheel coiling technique never spread and was restricted to a few functional categories of vessels (Roux 2008). In other words, the potter's wheel became prevalent through different scenarios but only in situations where the whole ceramic production was in the hands of specialised artisans. This suggests that the general adoption of the potter's wheel depended on the evolution of the social structures. As long as societies did not achieve their mutation towards craft specialisation, it could not become prevalent and participate to cumulative technical evolution. By extension, the spreading of technological systems appears as determined by the social history of ancient groups or more generally the history of techniques seems to be conditioned by the history of social structures. Following Braudel (1958) according to whom change in social structures mark discontinuities, we conclude that cumulative technical evolution, exemplified here by the spreading of the potter's wheel, appears as regulated by major social mutations, i.e. major discontinuities. Figure 7 gives a synoptic view of the general construct.

\section{Conclusion}

The scope of this paper was to question the spreading of technical traits and its significance in terms of continuity and discontinuity. The archaeological data interpreted by reference to a transmission sociological model show that, in the Levant, the potter's wheel spread both through demic and cultural processes. This does not mean, however, that such a spreading was not constrained by specific conditions. When examining the social context of the wheel-made ceramic production, it appears that the potter's wheel has diffused only when the whole ceramic production was in the hands of craft specialists. As a result, it can be said that the general adoption of the potter's wheel has depended on the evolution of social structures. 


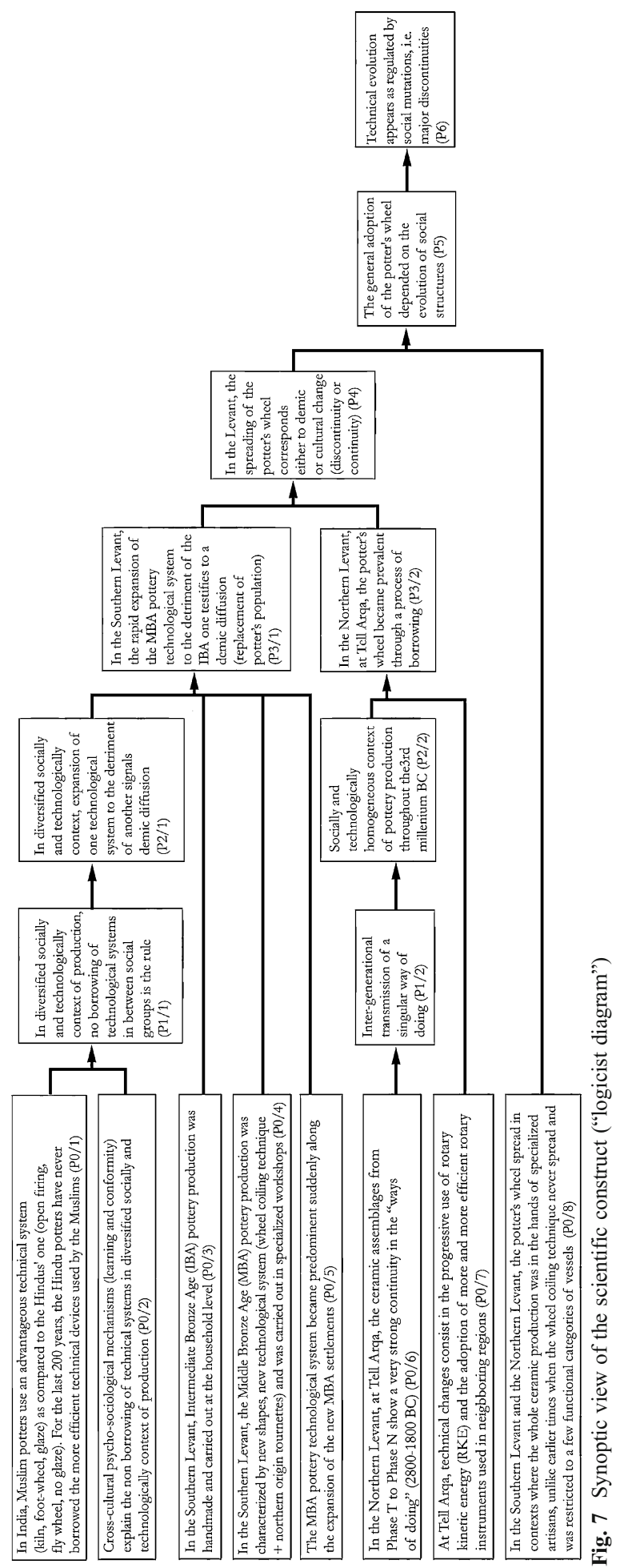


As specified by Creswell, the evolution of techniques and their cumulative trajectory cannot be reduced to social Darwinism because of the preponderant part of the society in the stimulation and determination of techniques, this part implying that sociological selection is probably to be distinguished from biological selection (Creswell 1996). Although the dual inheritance theory (Boyd and Richerson 1985; Richerson and Boyd 2005) does acknowledge that social and biological selection operates according to different mechanisms, it does not take into account the social conditions for triggering individual and social learning as well as the nature of the trait to be learned. It means that social learning models for explaining specific historical narratives are still to be worked out and tested against empirical data. This is probably one of the most important tasks in contemporary archaeology if one wants to elucidate the forces underlying evolution of material culture and unravel the hidden discontinuities.

Acknowledgements I want here to warmly thank J. P. Thalmann who invited me to analyse the ceramic assemblages of Tell Arqa (Lebanon), N. Panitz-Cohen and A. Mazar who gave me access to the Beth Shean material, E. Marcus who kindly offered me to examine the Tel Ifshar material and lastly the Israel State Collections of Antiquities for providing access to the Intermediate Bronze Age material. Research on ceramic assemblages in Israel was made possible thanks to researchers' month allowances granted by the CRFJ (Centre de Recherches Français de Jerusalem, Jerusalem French Research Center). Our special thanks also to the lab "Prehistory and technology" (CNRS) who funded the ethnoarchaeological investigations in India. At last, I want to thank two anonymous reviewers for relevant comments, which helped in improving a first version of this paper, as well as Jim Skibo for improving the English. Illustrations have been made by G. Monthel (CNRS, UMR 7055).

\section{References}

Amiran, R., \& Shenhav, D. (1984). Experiments with an ancient potter's wheel. In P. M. Rice (Ed.), Pots and potters. Current approaches in ceramic archaeology (pp. 107-112). Los Angeles: University of California, Institute of Archaeology.

Baum, W. M., Richerson, P. J., Efferson, C. M., \& Paciotti, B. M. (2004). Cultural evolution in laboratory microsocieties including traditions of rule giving and rule following. Evolution and Human Behavior, 25, 305-326.

Beck, P. (1985). The Middle Bronze Age IIA pottery from Aphek, 1972-1984: first summary. Tel Aviv, 12, 181-203.

Berry, J. W., Poortinga, Y. H., Segall, M. H., \& Dasen, P. R. (2002). Cross-cultural psychology: Research and applications (2nd ed.). Cambridge: Cambridge University Press.

Boyd, R., \& Richerson, P. J. (1985). Culture and the evolutionary process. Chicago: University of Chicago Press.

Braudel, F. (1958). Histoire et Sciences sociales: La longue durée. Annales. Histoire, Sciences Sociales, 13, $725-753$.

Bril, B. (2002). L'apprentissage de gestes techniques: ordre de contraintes et variations culturelles. In B. Bril \& V. Roux (Eds.), Le geste technique. Réflexions méthodologiques et anthropologiques (pp. 113150). Ramonville Saint-Agne: Editions Erès.

Collard, M., Edinborough, K., Shennan, S., \& Thomas, M. G. (2010). Radiocarbon evidence indicates that migrants introduced farming to Britain. Journal of Archaeological Science, 37, 350-359.

Covello-Paran, K. (2009). Socio-economic aspects of Intermediate Bronze Age Village in the Jezreel Valley. In P. J. Parr (Ed.), The levant in transition (pp. 9-20). Londres: Maney.

Creswell, R. (1994). La nature cyclique des relations entre le technique et le social. Approche technologique de la chaîne opératoire. In B. Latour \& P. Lemonnier (Eds.), De la préhistoire aux missiles balistiques. L'intelligence sociale des techniques (pp. 275-289). Paris: Editions La découverte.

Creswell, R. (1996). Prométhée ou Pandore? Propos de technologie culturelle. Paris: Kimé. 
Degoy, L. (2008). Technical traditions and cultural identity: An ethnoarchaeological study of Andhra Pradesh potters. In M. Stark, B. Bowser, \& L. Horne (Eds.), Cultural transmission and material culture. Breaking down boundaries (pp. 199-222). Tucson: Arizona University Press.

Dever, W. G. (1995). Social structure in the Early Bronze IV period in Palestine. In T. E. Levy (Ed.), The archaeology of society on the holy land (pp. 282-296). London: Leicester University Press.

Efferson, C., Lalive, R., Richerson, P. J., McElreath, R., \& Lubell, M. (2008). Conformists and mavericks: the empirics of frequency-dependent cultural transmission. Evolution and Human Behavior, 29, 56-64.

Gallay, A. (1986). L'archéologie demain. Paris: Belfond.

Gallay, A. (2007). The decorated marriage jars of the inner delta of the Niger (Mali): essay of archaeological demarcation of an ethnic territory. The Arkeotek Journal, 1. www.irit.fr/thearkeotekjournal.

Gallay, A. (2011). Une ethnoarchéologie théorique. Paris: Errance.

Gardin, J.-C. (1980). Archaeological constructs: An aspect of theoretical archaeology. Cambridge: Cambridge University Press.

Gelbert, A. (2003). Traditions céramiques et emprunts techniques dans la vallée du fleuve Sénégal. Paris: Editions de la Maison des sciences de l'homme et Editions Epistèmes. CD ROM bilingue.

Gophna, R. (1992). The Intermediate Bronze Age. In A. Ben-Tor (Ed.), The archaeology of ancient Israel (pp. 126-158). New Haven: Yale University Press, The Open University of Israel.

Gophna, R. (2009). A short-lived settlement system and a lengthy period: The Intermediate Bronze Age ('Intermediate Bronze Age') on the coastal plain of Israel. In P. J. Parr (Ed.), The levant in transition (pp. 34-37). Londres: Maney.

Goren, Y. (1996). The Southern Levant in the Early Bronze Age IV: the petrographic perspective. Bulletin of the American Schools of Oriental Research, 303, 33-72.

Gosselain, O. P. (2000). Materializing identities: an African perspective. Journal of Archaeological Method and Theory, 7, 187-217.

Gosselain, O. P. (2008). Mother Bella was not a Bella. Inherited and transformed traditions in Southwestern Niger. In M. Stark, B. Bowser, \& L. Horne (Eds.), Cultural transmission and material culture. Breaking down boundaries (pp. 150-177). Tucson: Arizona University Press.

Henrich, J. (2001). Cultural transmission and the diffusion of innovations: adoption dynamics indicate that biased cultural transmission is the predominant force in behavioral change. American Anthropologist, 103, 992-1013.

Henrich, J., \& Boyd, R. (1998). The evolution of conformist transmission and the emergence of betweengroup differences. Evolution and Human Behavior, 19, 215-242.

Henrich, J., \& McElreath, R. (2003). The evolution of cultural evolution. Evolutionary Anthropology, 12, $132-135$.

Ilan, D. (1995). The rise of internationalism: The Middle Bronze Age. In T. E. Levy (Ed.), The archaeology of society on the holy land (pp. 297-319). London: Leicester University Press.

Ilan, D., \& Marcus, E. (in press). Pottery of the Middle Bronze Age IIa. In S. Gitin (Ed.) The Ancient pottery of Israel and its neighbors. Jerusalem: W. F. Albright Institute of Archaeological Research, Israel Exploration Society and the Israel Antiquities Authority.

Ingold, T. (2001). Beyond art and technology: The anthropology of skill. In M. B. Schiffer(Ed.), Anthropological perspective on technology (pp. 17-32). Albuquerque: University of New Mexico Press.

Kandler, A., \& Steele, J. (2010). Social Learning, economic inequality and innovation diffusion. In M. J. O’Brien \& S. J. Shennan (Eds.), Innovation in cultural systems. Contributions from evolutionary anthropology (pp. 193-214). Cambridge: The MIT Press.

Kempinski, A. (1992). The middle bronze age. In A. Ben-Tor (Ed.), The archaeology of ancient Israël (pp. 159-210). New Haven: Yale University Press, The Open Uniersity of Israël.

Knappett, C. (2005). Thinking through material culture: An interdisciplinary perspective. Philadelphia: University of Pennsylvania Press.

Kochavi, M. \& Yadin, E. (2002). Typological analysis of the MBIIA pottery from Aphek according to its stratigraphic provenience. In M. Bietak (Ed.), The Middle Bronze Age in the Levant (pp. 189-225). Proceedings of an International Conference on Middle Bronze Age IIA ceramic material, Vienna 24th26th of January 2001. Wien: Verlag der Osterreichischen Akademie der Wissenschaften.

Lemonnier, P. (1981). Le commerce inter-tribal des Anga de Nouvelle-Guinée. Journal de la Société des océanistes, 37, 39-75.

Lemonnier, P. (Ed.). (1993). Technological choices: Transformation in material cultures since the Neolithic. London: Routledge.

Maeir, A. M. (2010). In the Midst of the Jordan. The Jordan Valley during the Middle Bronze Age (circa 2000-1500 BCE). Archaeological and Historical Correlates. Wien: Österreichische Akademie der Wissenschaften. 
Maeir, A., \& Yellin, J. (2007). Instrumental Neutron Activation Analysis of selected pottery from Tel BethShean and the Central Jordan Valley. In A. Mazar \& R. A. Mullins (Eds.), Excavations at Tel beth-Shean 1989-1996. Volume II, The Middle and late Bronze Age strata in Area R (pp. 554-571). Jerusalem: The Israel Exploration Society, The Institute of Archaeology, The Hebrew University of Jerusalem.

Marcus, E. S., Porath, Y., \& Paley, S. M. (2008). The Early Middle Bronze Age IIa phases at Tel Ifshar and their external relations. In M. Bietak (Ed.), Agypten und Levante/Egypt and the Levant XVIII (pp. 221244). Wien: Österreichische Akademie der Wissenschaften.

Margueron, J.-C. (2004). Mari: métropole de l'Euphrate au IIIe et au début du IIe millénaire avant J.-C. Paris: Picard, Editions Recherches sur les Civilisations.

Mesoudi, A. (2007). Using the methods of social psychology to study cultural evolution. Journal of Social Evolutionary and Cultural Psychology, 1, 35-58.

Mesoudi, A. (2008). An experimental simulation of the "copy-successful-individuals" cultural learning strategy: adaptative landscapes, producer-scrounger dynamics and informational access costs. Evolution and Human Behavior, 29, 350-363.

Mesoudi, A. (2010). The experimental study of innovations. In M. J. O’Brien \& S. J. Shennan (Eds.), Innovation in cultural systems. Contributions from Evolutionary Anthropology (pp. 175-191). Cambridge: The MIT Press.

Mesoudi, A., \& O’Brien, M. J. (2009). Placing archaeology within a unified science of cultural evolution. In S. J. Shennan (Ed.), Pattern and process in cultural evolution (pp. 21-29). Berkeley: University of California.

Moscovici, S. (Ed.). (1984). Psychologie sociale. Paris: Presses Universitaires de France.

O'Brien, M. J., \& Bentley, R. A. (2011). Stimulated variation and cascades: two processes in the evolution of complex technological systems. Journal of Archaeological Method and Theory, 18, 309-337.

Paley, S. M., \& Porath, Y. (1997). Early middle bronze age IIa remains at Tel el-Ifshar, Israel: A preliminary report. In E. O. Oren (Ed.), The hyksos: New historical and archaeological perspectives (pp. 369-379). Philadelphia: The University Museum, University of Pennsylvania.

Powell, C. (1995). The nature and use of ancient Egyptian potter's wheel. In B. J. Kemp (Ed.), Amarna Reports VI (pp. 309-335). London: Egypt Exploration Society.

Reed, E. S., \& Bril, B. (1996). The primacy of action in development. A commentary of N. Bernstein. In M. L. Latash, M. T. Turvey, \& N. A. Bernstein (Eds.), Dexterity and its development (pp. 431-451). Mahwah: Lawrence Erlbaum Associates.

Richerson, P. J., \& Boyd, R. (2005). Not by genes alone. How culture transformed human evolution. Chicago: The University of Chicago Press.

Roobaert, A., \& Trokay, M. (1990). Surface finds. Abr-nahrain, suppl. 2, 121-125.

Roux, V. (2003). A dynamic systems framework for studying technological change: application to the emergence of the potter's wheel in the southern Levant. Journal of Archaeological Method and Theory, 10, 1-30.

Roux, V. (2008). Evolutionary trajectories of technological traits and cultural transmission: A qualitative approach to the emergence and disappearence of the ceramic wheel-fashioning technique in the southern Levant during the fifth to the third millenia BC. In M. Stark, B. Bowser, \& L. Horne (Eds.), Cultural transmission and material culture. Breaking down boundaries (pp. 82-104). Tucson: Arizona University Press.

Roux, V. (2009). The Potter's wheel in Middle Bronze II in the Southern Levant: Technological study of the Beth Shean ceramics. The Arkeotek Journal, 3. www.thearkeotekjournal.org.

Roux, V. (2010). Technological innovations and developmental trajectories: Social factors as evolutionary forces. In M. J. O’Brien \& S. J. Shennan (Eds.), Innovation in cultural systems. Contributions from Evolutionary Anthropology (pp. 217-234). Cambridge: The MIT Press.

Roux, V. (in press). Cultural transmission, migration and plain wheel-made pottery in the MB II Southern Levant. In C. Glatz (Ed.), Plain and simple. The evolution and significance of plain pottery traditions in the second millennium BC Near East and East Mediterranean. Walnut Creek: The Left Coast Press.

Roux, V., \& Corbetta, D. (1989). The potter's wheel. Craft specialization and technical competence. New Delhi: Oxford \& IBH. (http://www.arkeotek.org/ebooks/potterswheel.pdf)

Roux, V., \& de Miroschedji, P. (2009). Revisiting the history of the potter's wheel in the southern Levant. Levant, 41, 155-173.

Roux, V., \& Courty, M.-A. (2013). Introduction to discontinuities and continuities: theories, methods and proxies for an historical and sociological approach to evolution of past societies. Journal of Archaeological Method and Theory

Saraswati, B., \& Behura, N. K. (1964). Pottery techniques in peasant India. Calcutta: Anthropological Survey of India. 
Schiffer, M. B. (2008). Transmission processes: A behavioral perspective. In J. M. O’Brien (Ed.), Cultural transmission and archaeology: Issues and case studies (pp. 102-111). Washington: Society for American Archaeology.

Schiffer, M. B. (2011). A Behavioral archaeologist responds. Journal of Archaeological Method and Theory, 18, 336-348.

Schiffer, M. B., \& Skibo, J. M. (1997). The explanation of artifact variability. American Antiquity, 62, $27-50$.

Shennan, S. J. (Ed.). (2009). Pattern and process in cultural evolution. Berkeley: University of California.

Shennan, S. J. (2011). Descent with modification and the archaeological record. Philosophical Transactions of the Royal Society B, 36, 1070-1079.

Simondon, G. (1958). Du mode d'existence des objets techniques. Paris: Aubier.

Skibo, J. M., \& Schiffer, M. B. (2001). Understanding variability and change: A behavioral framework. In M. B. Schiffer (Ed.), Anthropological perspectives on technology (pp. 139-149). Albuquerque: University of New Mexico Press.

Sodhi, G. J. (2006). Traditional potters and technological change in a North Indian Town. Sociological Bulletin, 55, 367-382.

Stark, M. (Ed.). (1998). The archaeology of social boundaries. Washington: Smithsonian Institution Press.

Stark, M., Bowser, B., \& Horne, L. (Eds.). (2008). Cultural transmission and material culture. Breaking down boundaries. Tucson: Arizona University Press.

Thalmann, J.-P. (2006). Tell Arqa. 1. Les Niveaux de l'âge du Bronze (3 vol.). Beyrouth: Institut Français du Proche-Orient. 